within autosomal genes are unavailable for assay validation. However, male samples are equivalent to a heterozygous deletion in female samples. Consequently, female samples with heterozygous deletions of an X chromosomal segment are comparable to normal male samples.

RD-PCR was also tested in a prospective study in hemophilia A families to detect heterozygous deletions in $\mathrm{X}$ chromosomal segments. RDPCR assays were designed for exons 6 and 7 of the factor VIII gene. Eight females from two hemophilia A fam alidation of new assays; (iv) utilization of a generic endogenous internal dosage control to eliminate preparation and manipulation errors; $(v)$ detection of gene dosage over a wide dynamic range (3); (vi) tolerance toward genomic DNA of variable quality (J. Shi, Q. Liu, V.Q. Nguyen, and S.S. Sommer, submitted); and (vii) uniform and unbiased performance across regions of variable sequence context and GC content.

\section{ACKNOWLEDGMENTS}

The authors would like to thank Xuemin Li for preparation of the blinded DNA samples.

\section{COMPETING INTERESTS STATEMENT}

The authors declare that they have no competing interests.

\section{REFERENCES}

1.Stenson, P.D., E.V. Ball, M. Mort, A.D. Phillips, J.A. Shiel, N.S. Thomas, S. Abeysinghe, M. Krawczak, et al. 2003. Human Gene Mutation Database (HGMD): 2003 update. Hum. Mutat. 21:577-581.

2.Armour, J.A., D.E. Barton, D.J. Cockburn, and G.R. Taylor. 2002. The detection of large deletions or duplications in genomic DNA. Hum. Mutat. 20:325-337.

3.Liu, Q., X. Li, J.S. Chen, and S.S. Sommer. 2003. Robust dosage-PCR for detection of heterozygous chromosomal deletions. BioTechniques 34:558-570.

4.Liu, Q. and S.S. Sommer. 1998. Subcycling-PCR for multiplex long-distance amplification of regions with high and low GC content: application to the inversion hot- spot in the factor VIII gene. BioTechniques 25:1022-1028.

5.Miyada, C.G. and R.B. Wallace. 1987. Oligonucleotide hybridization techniques. Methods Enzymol. 154:94-107.

6.Yoshitake, S., B.G. Schach, D.C. Foster, E.W. Davie, and K. Kurachi. 1985. Nucleotide sequence of the gene for human factor IX (anti-hemophilic factor B). Biochemistry 24:3736-3750.
Received 6 April 2004; accepted 28 May 2004.

Address correspondence to Steve S. Sommer, Chair, Departments of Molecular Genetics and Molecular Diagnosis, City of Hope National Medical Center, 1500 East Duarte Road, Duarte, CA 91010-3000, USA.e-mail:sommerlab@coh.org

\title{
Scalable high-throughput micro-expression device for recombinant proteins
}

Rebecca Page, Kin Moy, Eric C. Sims, Jeffrey Velasquez, Brendan McManus, Carina Grittini, Thomas L. Clayton, and Raymond C. Stevens

Joint Center for Structural Genomics and Department of Molecular Biology, The Scripps Research Institute, La Jolla, CA, USA

BioTechniques 37:364-370 (September 2004)

The large-scale expression and purification of recombinant proteins needed for structural studies is time-consuming and expensive, especially when costly reagents, such as selenomethionine (SeMet) or ${ }^{15} \mathrm{~N} /{ }^{13} \mathrm{C}$-labeled nuclear magnetic resonance (NMR) medium, are required. Small-scale screens are being developed to identify which targets express and are soluble prior to large-scale expression (1-7). Although these screens are designed for a 96sample, small-scale format, none adequately predicts the reliable expression behavior with scaled-up milliliter and liter fermentations, which has been a challenge for researchers in the field.

We have adapted a low-cost, highvelocity incubating Glas-Col Vertiga shaker (Glas-Col, LLC, Terre Haute, IN, USA; Figure 1A) to develop an efficient, high-throughput Escherichia coli microliter-scale expression screening protocol that accurately predicts protein behavior expressed in largescale (milliliter and liter) fermentation conditions. The apparatus shakes cultures in three dimensions at speeds of up to $1000 \mathrm{rpm}$, allowing smallscale (approximately $500 \mu \mathrm{L}$ ) cultures grown in 2-mL 96-deep-well blocks to achieve absorbances $\left(\mathrm{A}_{600}\right)$ as high as 10-20. This generates sufficient material for the analysis of expression, solubility, and binding to affinity purification matrices. Moreover, this screening strategy has also been used to identify clones that express and are soluble under SeMet (8) or ${ }^{15} \mathrm{~N} /{ }^{13} \mathrm{C}$-labeled expression conditions that are necessary for the production of labeled recombinant proteins for direct structural analysis. The Glas-Col Vertiga shaker can be used to screen for soluble expression clones under native, SeMet, and ${ }^{15} \mathrm{~N} /{ }^{13} \mathrm{C}$-labeled expression conditions.

Microscale expression using the Glas-Col Vertiga shaker is carried out as follows. First, overnight cultures are prepared with $250 \mu \mathrm{L}$ sterile $2 x y t$ media containing antibiotic $(0.3 \mathrm{mM}$ ampicillin) in sterile 2-mL, 96-deep-well, round-bottom blocks (USA Scientific, Ocala, FL, USA). Each well is then inoculated with $1 \mu \mathrm{L}$ glycerol stocks of expression clones (also stored in a 96-well format) using a multichannel pipet. Once sealed with a sterile, porous plate cover (USA Scientific), the blocks are placed in the Glas-Col Vertiga shaker, and cultures are grown overnight at $37^{\circ} \mathrm{C}$, shaking at $550 \mathrm{rpm}$. 
Expression under native conditions is carried out using $500 \mu \mathrm{L}$ sterile Terrific Broth (TB or $2 \times$ TB) media prepared with $100 \mathrm{mM}$ MOPS, pH 7.4, and antibiotic, while expression under SeMet conditions is carried out using sterile complete media with $1 \mu \mathrm{g} / \mathrm{mL} \mathrm{FeSO}$, $0.8 \mathrm{mM}$ SeMet, and antibiotic. Blocks containing the overnight cultures are then centrifuged at $5000 \times g$ to pellet the $E$. coli cells, the supernatants are discarded, and the pellets are resuspended in $100 \mu \mathrm{L}$ fresh media (TB or SeMet, as appropriate). The freshly prepared expression blocks are then inoculated with $25 \mu \mathrm{L}$ of the resuspended overnight culture. After sealing each expression block with a porous plate cover, blocks are placed in the GlasCol Vertiga shaker and grown at 900 rpm and $37^{\circ} \mathrm{C}$. When the culture $\mathrm{A}_{600}$ reaches approximately 3 (about $1.5 \mathrm{~h}$ following inoculation at $37^{\circ} \mathrm{C}$; spectrophotometer wavelength, $600 \mathrm{~nm}$ ), expression is induced [final concentration of $0.2 \%(\mathrm{w} / \mathrm{v})$ L-arabinose (Sigma, St. Louis, MO, USA)] and cultures are allowed to shake at $900 \mathrm{rpm}$ and $37^{\circ} \mathrm{C}$ for an additional 4-5 h. The final average culture $\mathrm{A}_{600}$ is usually between 10 and 20. Blocks are then centrifuged at $5000 \times g$ for $10 \mathrm{~min}$ to pellet the cells, and the supernatants are discarded. Blocks with pelleted cells are then analyzed for expression or sealed with a rubber plate seal and stored at $-80^{\circ} \mathrm{C}$ for future analysis. In addition to the L-arabinose expression system (pBAD vector; Invitrogen, Carlsbad, CA, USA), similar microliter-scale and milliliter/liter experiments have also been carried out with the T7 expression system (pET vectors; Novagen, Madison, WI, USA).

Expression and solubility are evaluated using sodium dodecyl sulfate polyacrylamide gel electrophoresis (SDS-PAGE) and Western blot analysis (His-tag antibodies). First, frozen bacterial cell pellets are placed at room temperature and allowed to thaw slightly. Cells are then thoroughly resuspended in $100 \mu \mathrm{L}$ of MP lysis buffer A [ $50 \mathrm{mM}$ Tris, $\mathrm{pH} 7.5,50 \mathrm{mM}$ sucrose, $1 \mathrm{mM}$ EDTA, $0.25 \mathrm{mM}$ tris-(2-carboxyethyl) phosphine hydrochloride (TCEP)] with $1.0 \mathrm{mg} / \mathrm{mL}$ lysozyme and $0.25 \mu \mathrm{L} / \mathrm{mL}$ Benzonase $^{\circledR}$ (Novagen). After incubating at room temperature for $15 \mathrm{~min}, 100$ $\mu \mathrm{L}$ of MP lysis buffer B (10 mM Tris, $\mathrm{pH} 7.5,50 \mathrm{mM} \mathrm{KCl}, 10 \mathrm{mM} \mathrm{MgCl}, 1$ mM EDTA, $0.25 \mathrm{mM}$ TCEP) are added to each well and incubated for an additional 15 min. After mixing, $10 \mu \mathrm{L}$ samples of the lysate from each well are removed and added to the SDSPAGE sample buffer. These samples represent the "total lysate" fractions. Samples are then centrifuged at 6100x $g$ for $15 \mathrm{~min}$ to pellet cell debris. Following centrifugation, $20 \mu \mathrm{L}$ of the supernatant are removed for SDS-PAGE analysis. These samples represent the "soluble" fractions.

If desired, the soluble fraction is then purified using immobilized metalaffinity chromatography (IMAC). A $400-\mu \mathrm{L}, 0.45-\mu \mathrm{m}$ filter-containing $96-$ well microplate is used for the load, wash, and elution steps, and a $450-\mu \mathrm{L}$ 96-well plate is placed underneath the filter plate to collect the flow through. One hundred microliters of a $50 \%$ slurry of $\mathrm{Co}^{2+}$-charged metal-affinity resin (TALONTM Superflow; BD Biosciences Clontech, Palo Alto, CA, USA) are added to each well of the filter plate and equilibrated with $300 \mu \mathrm{L}$ of equilibration buffer (1:1 mixture of MP lysis buffers A and B). Equilibration buffer is removed by centrifugation at $300 \times g$ for 1 min. Clarified lysate supernatants are then added to each well and gently mixed by slowly pipetting up and down for 10 repetitions. The resin is allowed to settle to the bottom of each well and is then centrifuged as before, with new collection plates underneath to collect soluble lysate flowthrough fractions. The resin is then washed once with MP wash buffer $(25 \mathrm{mM}$ Tris, pH 7.8, $150 \mathrm{mM} \mathrm{NaCl}$, $5 \mathrm{mM}$ imidazole, 0.25
$\mathrm{mM}$ TCEP) and centrifuged as before, saving the flow-through fractions in a third plate. The bound proteins are eluted from the IMAC resin using MP elution buffer $(25 \mathrm{mM}$ Tris, $\mathrm{pH} 7.8$, $150 \mathrm{mM} \mathrm{NaCl}, 150 \mathrm{mM}$ imidazole, $0.25 \mathrm{mM}$ TCEP). The resin is slowly resuspended with $50 \mu \mathrm{L}$ of elution buffer, after which the resin beads are allowed to settle for $10 \mathrm{~min}$. The filter plates are then centrifuged a final time, using a new $450-\mu \mathrm{L}$ 96-well plate to collect the eluate. Purified proteins can be used for additional analytical studies, such as mass spectrometry or size exclusion chromatography, as desired. A complete analysis of recombinant protein expression is performed by running 4\%-20\% SDS-PAGE gels of the total lysate, soluble, flow-through (unbound), and eluate fractions.

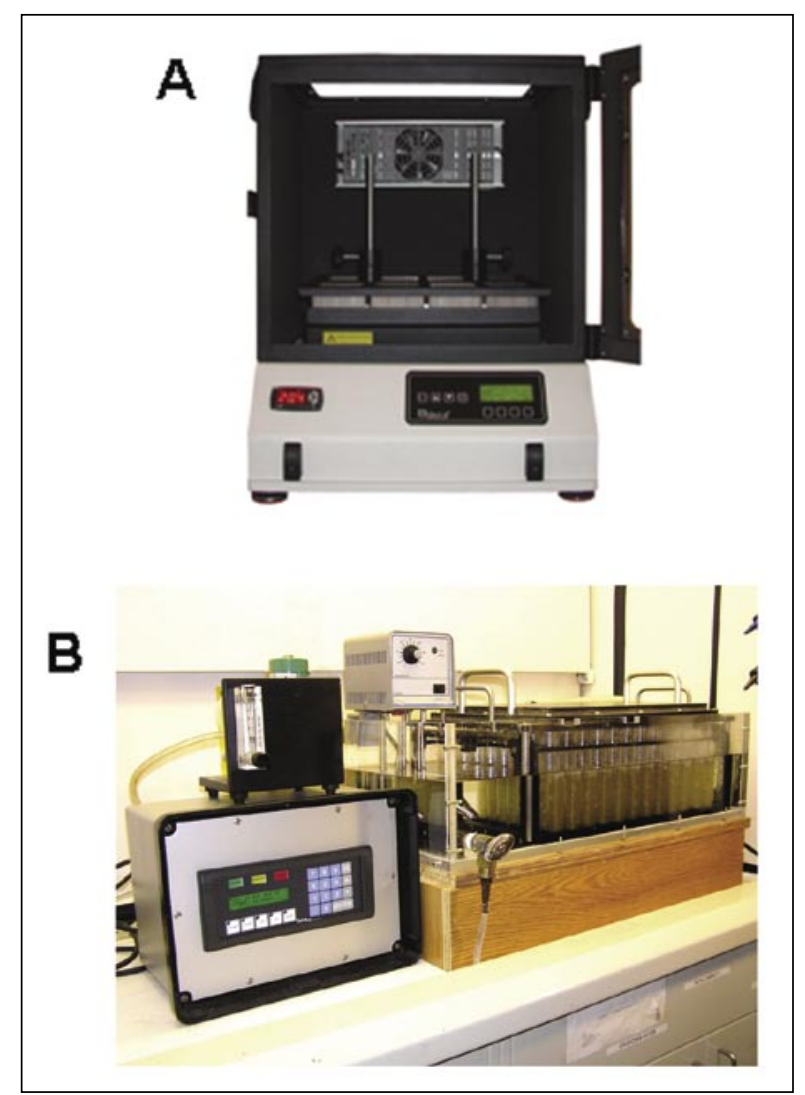

Figure 1. Glas-Col Vertiga microliter and Genomics Institute of the Novartis Research Foundation (GNF) milliliter expression systems. (A) Glas-Col Vertiga microliter-scale expression system. A low-cost vertical shaker apparatus adapted for the development of a scalable high-throughput Escherichia coli micro-expression screening. (B) GNF 96-well milliliter fermenter (9). A typical run includes the growth of approximately $65 \mathrm{~mL}$ of growth media, grown to an absorbance $\left(\mathrm{A}_{600}\right)$ of 10-20 using media conditions similar to the microliter-scale expression experiments, with oxygen supplementation. 
Table 1. Comparison List of Microliter-Expressed and Scaled-Up Expressed Proteins

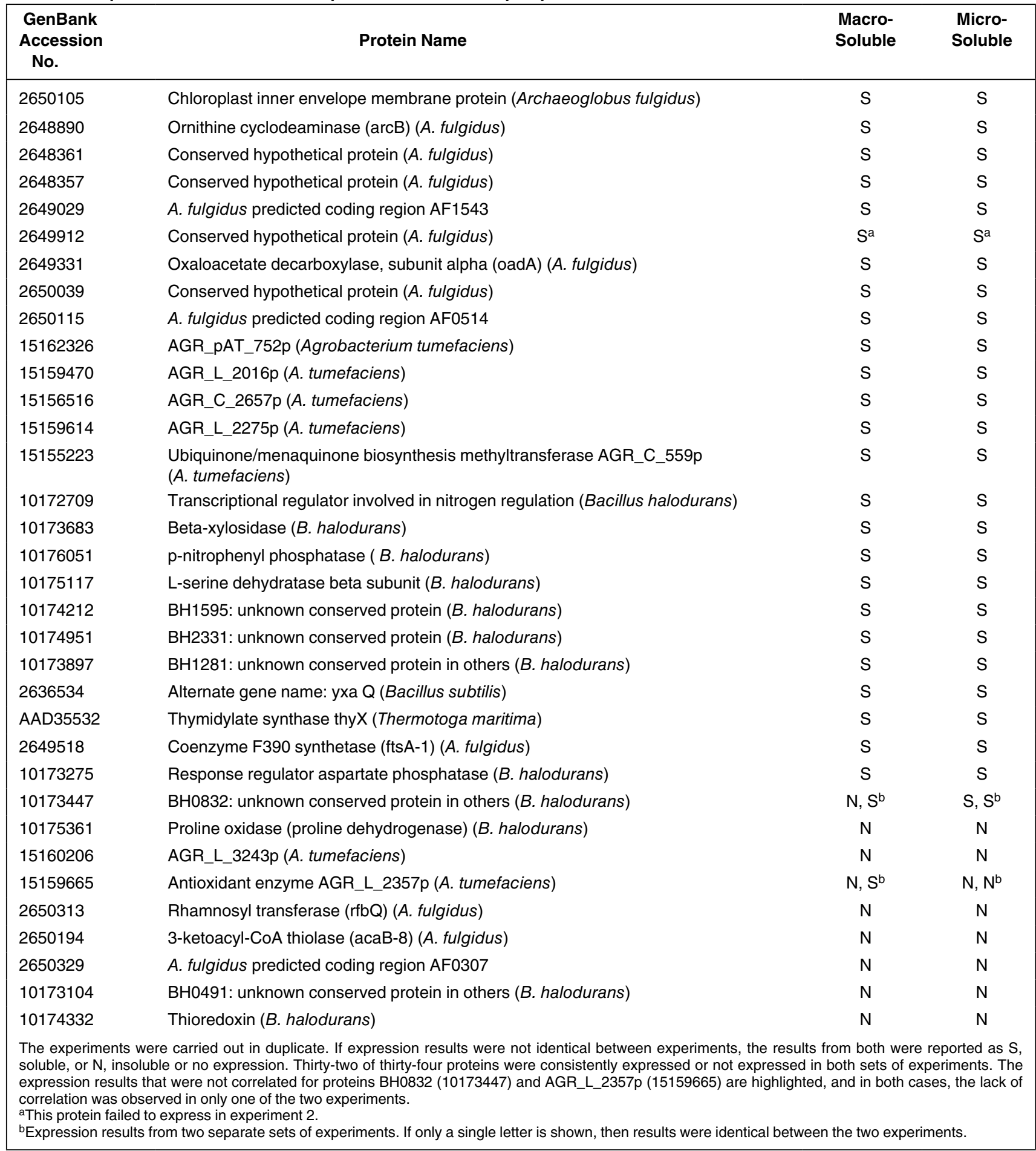

For comparison to larger-scale fermentation behavior, 34 proteins were expressed using the microliter-scale expression protocol under native conditions and expressed again using the Genomics Institute of the Novartis Research Foundation (GNF; San Diego,
CA, USA) 96-well milliliter fermenter (Figure 1B). This experiment was carried out in duplicate. Targets expressed in the GNF 96-well fermenter were purified as outlined by Lesley, et al. (9), with purity and yield determined by SDS-PAGE. Most samples were further analyzed using Western blot analysis with an anti-His antibody (Sigma) using standard protocols. Of the 34 proteins tested, 32 consistently expressed (or did not express) in both microliter and larger-scale volumes, illustrating a high level of scalability and correlation in 
the expression levels of soluble protein between the Vertiga screening trials and large-scale growth conditions (Table 1). In contrast, without the Vertiga shaker, the correlation between microliter- and milliliter- (and liter) scale expression is much lower (data not shown). The two proteins that behaved differently between micro- and macro-expression, BH0832 (GenBank ${ }^{\circledR}$ accession no. 10173447) and AGR_L_2357p (accession no. 15159665), did so in only one of the two experiments; in the second, the micro- and macro-expression behavior was identical for both proteins (Table 1). Finally, eukaryotic proteins from Saccharomyces cerevisiae and viral proteins from the Severe Acute Respiratory Syndrome (SARS) virus have also been successfully micro-expressed in E. coli using this device.

These results demonstrate that the microliter-scale expression protocol developed using the Vertiga vertical shaker can be used to accurately identify proteins that will express solubly in larger-scale fermentation conditions. Moreover, the results from these screens can be used to assess the solubility and expected protein yield for each potential protein target for both native and labeled $E$. coli recombinant expression. Future developments include using material directly from microliter-scale expression for biophysical analysis, including nanovolume crystallization (10) and other biophysical techniques currently being miniaturized.

\section{ACKNOWLEDGMENTS}

This work was supported in part by grant no. GM62411 (to I.A. Wilson, P.I., JCSG) from the National Institutes of Health (NIH) Protein Structure Initiative. We appreciate the assistance of Lee Clark, Jim Jasco from Glas-Col, Mark Knuth and Ciaran Cronin from Syrrx for the initial studies of the Vertiga system, and Scott Lesley, Mark Weselak, and Bob Downs for the GNF fermenter design.

\section{COMPETING INTERESTS STATEMENT}

The authors declare that they have no competing interests.

\section{REFERENCES}

1.Holz, C., O. Hesse, N. Bolotina, U. Stahl, and C. Lang. 2002. A micro-scale process for highthroughput expression of cDNAs in the yeast Saccharomyces cerevisiae. Protein Expr. Purif. 25:372-378

2.Shih, Y.-P., W.-M. Kung, J.-C. Chen, C.-H. Yeh, A.H.-J. Wang, and T.-F. Wang. 2002. High-throughput screening of soluble recombinant proteins. Protein Sci. 11:1714-1719.

3.Adams, M.W.W., H.A. Dailey, L.J. DeLucas, M. Luo, J.H. Prestegard, J.P. Rose, and B.C. Wang. 2003. The Southeast Collaboratory for Structural Genomics: a high-throughput gene to structure factory. Acc. Chem. Res. 36:191-198.

4.Nguyen, H., B. Martinez, N. Oganesyan, and K. Rosalind. 2004. An automated small-scale protein expression and purification screening provides beneficial information for protein production. J. Struct. Funct. Genomics 5:23-27.

5.Scheich, C., V. Sievert, and K. Büssow. 2003. An automated method for high-throughput protein purification applied to a comparison of His-tag and GST-tag affinity chromatography. BMC Biotechnol. 3:12-19.

6.Knaust, R.K.C. and P. Nordlund. 2001. Screening for soluble expression of recombinant proteins in a 96-well format. Anal. Biochem. 297:79-85.
7.Yokoyama, S. 2003. Protein expression systems for structural genomics and proteomics. Curr. Opin. Chem. Biol. 7:39-43.

8.Hendrickson, W.A., J.R. Horton, and D.M. LeMaster. 1990. Selenomethionyl proteins produced for analysis by multiwavelength anomalous diffraction (MAD): a vehicle for direct determination of three-dimensional structure. EMBO J. 9:1665-1672.

9.Lesley, S.A., P. Kuhn, A. Godzik, A.M. Deacon, I. Mathews, A. Kreusch, G. Spraggon, H.E. Klock, et al. 2002. Structural genomics of the Thermotoga maritima proteome implemented in a high-throughput structure determination pipeline. Proc. Natl. Acad. Sci. USA 99:11664-11669.

10.Santarsiero, B.D., D.T. Yegian, C.C. Lee, G. Spraggon, J. Gu, D. Scheibe, D.C. Uber, E.W. Cornell, et al. 2002. An approach to rapid protein crystallization using nanodroplets. J. Appl. Crystallogr. 35:278-281.

Received 19 April 2004; accepted 1 June 2004.

Address correspondence to Raymond C. Stevens, The Scripps Research Institute, 10550 North Torrey Pines Road, La Jolla, CA 92037,USA.e-mail: stevens@scripps.edu

\title{
Robust expression of transgenes in MCF-7 breast cancer cells is expression vector-dependent
}

\author{
Paul Winnard, Jr., Yelena Mironchik, and Venu Raman \\ The Johns Hopkins University, Baltimore, MD, USA
}

BioTechniques 37:370-374 (September 2004)

We are reporting that the in vivo protein expression in mammalian MCF-7 breast cancer cells can be highly dependent on the type of commercially available expression vectors used. Figure 1 is a representation of the vector backbones used and indicates the position of our genes of interest (denoted Insert) relative to the cytomegalovirus (CMV) promoter and simian virus 40 (SV40) poly(A) signal sequence in a pCMVTag4A vector (Stratagene, La Jolla, CA, USA), which resulted in an in-frame fusion at the 3' end with a $\mathrm{FLAG}^{\circledR}$ epitope sequence. Figure 1 also depicts the placement of these FLAG-tagged genes (including a TGA stop codon) into a pEF- $1 \alpha$ His/Myc vector (Invitrogen, Carlsbad, CA, USA) and their relative positions with respect to the elongation factor- $1 \alpha$ $(\mathrm{EF}-1 \alpha)$ promoter and bovine growth hormone (BGH) poly(A). Thus, except for the vector backbones, both fusion gene construct sequences were identical in the two vector systems. Sequencing analyses proved that each gene sequence was correct and in-frame with the FLAG sequence and stop codon. All plasmids were prepared using the Qiagen ${ }^{\circledR}$ Plasmid Midi Kits (Qiagen, Valencia, CA, USA). Initial transient 